\title{
Balateiros da Flota Paru: relações de trabalho, conhecimentos tradicionais e memória como experiência social
}

\section{Balateiros (latex extractor from balata) from Flota Paru: labor relations, traditional knowledge and memory as a social experience}

\author{
Marcelo Araújo da Silva ${ }^{1}$
}

\begin{abstract}
Resumo: O presente artigo resulta de pesquisas de longa duração analítica empreendida em municípios do oeste do Pará, inseridos na Flota do Paru, com dezenas de pessoas, que nos anos de 1930 a 1970, extraíram sistematicamente o látex da manilkara bidentata (balata). Buscou-se, por meio do registro de memórias e narrativas biográficas de balateiros ativos e ex-balateiros, reconstituir os contextos, processos, modos de fazer, viver e reproduzir o trabalho em suas experiências sociais. Demonstra-se a importância da reprodução sociocultural e ambiental dos conhecimentos tradicionais adquiridos por balateiros ao longo de décadas, no âmbito conceitual do patrimônio cultural imaterial. As inter-relações que envolvem balateiros, artesãos e floresta, constituem um modelo de sustentabilidade pautado em conhecimentos locais sobre as dinâmicas da floresta e as transformações naturais que ocorrem com a sazonalidade amazônica. Nesse movimento socioambiental se constituiu um modelo de sustentabilidade que é tecido a partir de complexas relações entre o meio cultural e o natural.
\end{abstract}

Palavras-chave: conhecimentos tradicionais, balateiros, memória social.

\begin{abstract}
This article is the result of long - term analytical research undertaken in western Pará municipalities, inserted in Flota Paru, with dozens of people, who from the 1930s to the 1970s systematically extracted latex from manilkara bidentata (balata). It was sought to reconstruct the contexts, processes, ways of doing, living and reproducing the work in their social experiences through the recording of memories and biographical narratives of active and ex-balateiros. It is demonstrated the importance of the socio-cultural and environmental reproduction of the traditional knowledge acquired by baleteiros during decades, in the conceptual scope of intangible cultural heritage. The interrelations involving baleteiros, craftsmen and forest, constitute a model of sustainability based on local knowledge on the dynamics of the forest and the natural transformations that occur with the Amazonian seasonality. In this socio-environmental movement, a model of sustainability was created that is woven from the complex relationships between the cultural and natural environments.
\end{abstract}

Keywords: traditional knowledge, balateiros, social memory.

\footnotetext{
${ }^{1}$ Mestrando do Programa de Pós-Graduação em Ciências da Sociedade da Universidade Federal do Oeste do Pará/Ufopa. E-mail: marceloaraujod@yahoo.com
} 


\section{Introdução}

Este trabalho foi construído a partir de disciplina cursada no Programa de Pósgraduação em Ciências da Sociedade da Universidade Federal do Oeste do Pará -Ufopa. No entanto, as investigações que subsidiaram a pesquisa para sua produção, foram realizadas anteriormente, entre os anos de 2012 e 2016, nos projetos de pesquisa e extensão executados no âmbito do Programa de Extensão Patrimônio Cultural na Amazônia (Pepca), e posteriormente do Núcleo de Estudos Interdisciplinares em Sociedades Amazônicas, Cultura e Ambiente (Sacaca), ambos vinculados ao Instituto de Ciências da Sociedade - Ufopa e apoiados pelo Conselho Nacional de Desenvolvimento Científico e Tecnológico-CNPq e pela Pró-Reitoria de Pesquisa, Pós-graduação e Inovação Tecnológica-Proppit da Ufopa.

Tem como objetivo a valorização da identidade, memória e cultura de balateiros também chamados de "soldados da borracha" e a estruturação de uma base teórica para a divulgação e reconhecimento das memórias de trabalho e conhecimentos tradicionais desses extrativistas, que num contexto de contato contínuo com a floresta e seus recursos, constituíram modos de criar, fazer e viver muito específicos, compondo características que os diferenciam da maioria das outras categorias de extrativistas. Sem perder de vista as relações mantidas em seu ambiente de trabalho na floresta, serão usadas as categorias indicadas por eles como forma de expressão, tentaremos explicá-las da melhor forma possível em respeito às exigências técnicas da escrita científica.

A pesquisa se desencadeou na Floresta Estadual do Paru (Flota Paru), no oeste do estado do Pará, especificamente nos municípios de Almeirim, Monte Alegre e Alenquer. A Flota Paru é uma Unidade de Conservação-UC estadual, de uso sustentável, administrada pela Secretaria de Meio Ambiente do Pará em conjunto com o Instituto de Desenvolvimento Florestal e Biodiversidade-Ideflor-bio e o Instituto do Homem e Meio Ambiente da Amazônia-Imazon.

Como resultado, identificamos durante as pesquisas de campo que apenas sete homens, numa faixa etária de 40 a 60 anos de idade, ainda realizam a extração do látex no município de Monte Alegre-PA. Os extrativistas que persistem no ofício de balateiro, realizam outras atividades laborativas além da exploração da balata, como por exemplo: 
a garimpagem de ouro, extrativismo de mandioca, pesca, etc. No entanto, o ofício de balateiro é a profissão pela qual se reconhecem, que Ihes outorga identidade individual e coletiva (POLLAK, 1992).

Observamos ainda que apesar de todas as dificuldades encontradas no trabalho, os balateiros assumem um profundo sentimento de tristeza pela perda do status de que gozavam e por terem permanecido por tantos anos num esquecimento social. Esse sentimento fica declarado na saudade: do balatal, dos amigos distantes e falecidos, das experiências vividas nas matas, muitas já contadas em trabalhos publicados, outras inenarráveis.

Para Moore (1987), a razão inata ou a dinâmica social de um determinado tipo de comportamento ou sentimento do grupo não pode ser satisfatoriamente conhecida, o que se pode compreender, é que a natureza humana é modificada e moldada pelos imperativos da vida em diferentes sociedades. Desta forma, a natureza humana é, na verdade altamente plástica, por isso se manifesta a capacidade humana para suportar o sofrimento e o abuso, por mais trágico e penoso que isso seja.

Em Godelier (1981) verificamos que as relações que se apresentam no caso dos balateiros, os processos de trabalho e as representações que dele emanam para a sociedade, atribuem valor positivo ou negativo a esses indivíduos, conforme a tarefa material e/ou simbólica que cumprem. O trabalho Ihes confere um status na hierarquia social em que se inserem. Mas, esse status e suas representações só fazem sentido no interior de um sistema de representações que define e legitima a repartição das tarefas necessárias à reprodução de uma dada sociedade.

Como aporte metodológico utilizou-se de entrevistas abertas e semiestruturadas para coleta de dados específicos, ao mesmo tempo em que se abre espaço para abarcar questões mais amplas da pesquisa, pautados no diálogo informal sobre as histórias e o cotidiano dos entrevistados. Durante as viagens a campo foram consultadas dezenas de pessoas entre homens e mulheres que ocuparam posições diversas na hierarquia da exploração da balata.

No mais, todas as indagações e respostas só foram possíveis graças ao uso da observação participante, nos termos usados por Oliveira (2000), como metodologia ca- 
paz de levar o pesquisar ao âmago das questões que se deseja ver respondidas, concorrendo para a construção de um aparato cultural rico para o pesquisador que realiza um profundo mergulho no mundo pesquisado.

\section{Trajetória da exploração gomífera na Amazônia brasileira}

O interesse pela produção de látex da Amazônia remonta 1743, quando o naturalista francês Charles Marie de La Condamine, registrando sua descia pelo Amazonas, vindo do Equador, observou que os nativos extraíam um líquido leitoso e viscoso com propriedades elásticas e impermeabilizantes de uma árvore grande e descorada, de gaIhos altos e flores delicadas. Da planta, que posteriormente seria chamada de Hevea brasiliensis, os índios moldavam botas, garrafas e brinquedos (BUENO, 2012).

Segundo Bueno (2012), Condamine voltou à França com certa quantidade de caoutchouc como era chamado o látex na Amazônia, o naturalista testou várias experiências com a nova descoberta, dentre elas uma roupa a prova d'água. Desta forma, a substância foi ganhando espaço na Europa.

No Brasil, apesar do período conhecido como ciclo da borracha ser comumente identificado como tendo ocorrido entre 1870 e 1910, constata-se que já a partir de 1840 toda a atividade econômica da região amazônica passou a girar em torno da extração do látex e da exportação do produto fabricado a partir de seu manuseio (BUENO, 2012).

De acordo com Bárbara Weinstein (1993), a penetração em novas zonas produtoras de borracha tornou-se preocupação especial já na década de 1860. Com o contínuo crescimento da demanda pelo produto no mercado mundial, a economia amazônica teve de aumentar sua produção do único modo que se ponderava possível, até então: via expansão da exploração do látex para seringais ainda não explorados rio acima, especialmente na província do Amazonas.

Em decorrência, Belém - capital do Pará, assumiu o papel de principal porto de escoamento da produção gomífera da região norte (BUENO, 2012). Para Weinstein (1993), embora o Pará se mantivesse à frente na produção da borracha até fins da década de 1880, a produção total da região decaiu rapidamente a partir de 1870 em diante. Nos primeiros anos apenas uns poucos municípios paraenses (Breves, Anajás, Melgaço e 
Gurupá) haviam respondido pela maior parte da borracha produzida, já na década de 1870 a extração da borracha havia se espalhado para o oeste, no baixo Xingu e no baixo Tapajós, no Pará, e de maneira ainda mais impressionante no Amazonas, nas zonas ricas em seringueiras dos rios Solimões, Madeira, Purus e Juruá.

Ainda que muito distantes do mercado exportador de Belém, a densa concentração de seringueiras ao longo desses rios e a relativa facilidade com que todos eles, com exceção do Madeira, podiam ser trafegados pela crescente frota de barcos a vapor do Amazonas, faziam com que fossem preferíveis aos trechos superiores do Xingu e do Tapajós, que corriam através de florestas também ricas em Heveas, mas minados por corredeiras e quedas d'água intransitáveis. Ainda assim, era em Belém que quase toda a borracha amazônica continuava a ser estocada, embalada e vendida para exportação (WEINSTEIN, 1993).

De 1870 a 1910, ocorreu o ápice da economia da borracha na região. Em 1871, a borracha alcançou o primeiro lugar nas exportações do Pará, com 4,8 milhões de quilos, contra 3,3 milhões de quilos de cacau (BUENO, 2012). Segundo Weinstein (1993), em fins da década de 1880 o valor anual das exportações de borracha havia subido $800 \%$ na comparação com os números de 1860, e a borracha representava aproximadamente $10 \%$ do comércio exterior do Brasil, apesar da acentuada expansão da economia cafeeira no período. A autora atesta que na virada do século, a borracha se tornaria o segundo produto brasileiro, constituindo $24 \%$ da exportação total do país.

O ciclo da borracha alterou sobremaneira, não apenas a economia, mas também as relações sociais e culturais no Brasil de finais do século XIX. As duas transformações mais expressivas desse período dizem respeito, de um lado, às formas brutais de exploração da floresta, e de outro, à riqueza proporcionada pela borracha, que alterou completamente dois centros urbanos, Manaus e Belém, os quais, de cidades inexpressivas, em pouco tempo passaram a figurar como importantes e modernas metrópoles brasileiras (WEINSTEIN, 1993 e BUENO, 2012).

Em Bueno (2012), constata-se que em janeiro de 1910, a indústria gomífera foi subitamente acometida de grave crise de "febre" da borracha. Após dois anos se expandindo, a Indian Rubber World, convidava seus leitores a não hesitarem em aceitar 
adquirir a borracha a 2 dólares a libra, advertindo ser pouco provável que os preços viessem a cair em futuro próximo. "Ninguém estava preparado para o violento mergulho que deu o mercado da borracha bruta nos meses restantes do ano de 1910, chegando a menos de 1,20 dólar já em novembro". (BUENO, 2012. pp.51).

Em 1910, a exportação de látex correspondia a 134 mil contos de réis, para uma produção de 34 mil toneladas. Três anos depois, não alcançava 70 mil contos de réis. A crise se manifestou na falência das casas aviadoras, na queda da produção dos seringais, no caos das finanças públicas. A partir de 1911 o preço do produto caiu vertiginosamente, à medida que uma quantidade cada vez maior da borracha de cultivo (originária da Ásia) chegava ao mercado internacional (BUENO, 2012).

Para Weinstein (1993), o esfacelamento do comércio de borracha, longe de um simples interlúdio, acabou sendo o começo de uma decadência de dez longos anos que iria atrofiar a economia extrativa da Amazônia. Segue a autora na afirmativa de que o elemento decisivo para a queda desse comércio, que representou o último golpe contra a economia da borracha na região, foi o resultado positivo do trabalho de botânicos com investimentos de empresários britânicos nas plantações de Hevea da Ásia, que começaram a produzir e, em grande escala. Com esse golpe final, "encerra-se o primeiro ciclo da borracha na Amazônia, e se iniciam outros capítulos da história da região, como "a triste história dos soldados da borracha" (BUENO, 2012, pp.52), e a exploração de balata no baixo amazonas-oeste do Pará.

\section{Os soldados da borracha}

Segundo Witkoski (2006), a figura do "soldado da borracha" surgiu no segundo grande fluxo de migração de nordestinos para a Amazônia brasileira, no contexto da Segunda Guerra Mundial, quando milhares de nordestinos foram arregimentados para cortar seringueiras e fornecer látex para as indústrias norte-americanas que alimentavam a Guerra. Desta forma, o Brasil cumpria com os acordos assinados em Washington em 1942, onde se posicionou do lado dos EUA na Guerra.

Nos anos de 1930, com o intuito de fixar o trabalhador rural nos sertões de Goiás e de Mato Grosso, o governo de Getúlio Vargas idealizou, em paralelo a sua política de in- 
dustrialização e substituição da mão-de-obra imigrante pela nacional, um plano chamado "Marcha para o Oeste", que logo se estendeu para a Amazônia. As secas no Nordeste eram a justificativa moral para oferecer essa opção àqueles que decidissem migrar. cenário internacional, entretanto, abalada pela eclosão da Segunda Guerra Mundial, colocou por terra o que se pretendia ser um plano de interiorização e colonização (BUENO, 2012).

O controle japonês sobre o abastecimento da borracha colocou aos países aliados o desafio de conseguir rapidamente um fornecedor daquele insumo, sobretudo para a indústria bélica. A Ásia, que poucos anos antes havia derrubado a cotação do valor da borracha, colocando por terra o ciclo que se desenvolvia no Brasil, estava agora amarrada pelos países do Eixo. O conflito bélico na Europa não deixava dúvidas quanto à necessidade de se encontrar um modelo que substituísse a produção da maior fornecedora de matéria-prima dos EUA, a Ásia, ainda que parcialmente (BUENO, 2012).

Perante esta configuração, o governo brasileiro, então, determinou que a melhor forma de fornecer mão-de-obra barata para os seringalistas poderem produzir mais borracha em menos tempo na região amazônica era direcionar a migração de nordestinos para a Amazônia, exatamente como havia ocorrido no final do século XIX.

É nesse cenário que surge na história local a figura do balateiro-extrativista de balata (Manilkara bidentada), também chamado de "soldado da borracha". A balateira faz parte da família das sapotáceas, assemelha-se à maçaranduba (Manilkara huberi) e, fornece madeira nobre de excelente qualidade, mas tem sido historicamente visada pelo seu látex. Dotada de propriedades semelhantes às da seringa (elasticidade e ductibilidade), esse látex tinha como principal destino econômico as indústrias dos Estados Unidos da América e Inglaterra que produziam e financiavam estoques bélicos para a manutenção da Segunda Guerra Mundial.

Embora tenha ocorrido concomitantemente ao segundo ciclo da borracha, a exploração de balata teve menor abrangência que a exploração desta primeira, mas foi também muito importante para a economia do norte do estado do Pará, especificamente nos municípios de Almeirim, Alenquer e Monte Alegre, onde esta pesquisa foi realizada. De acordo com Carvalho (2013), o comércio dessa matéria-prima movimentou a econo- 
mia de toda a região do Baixo Amazonas, alcançando a média de exportação de 300 a 400 toneladas por ano entre as décadas de 1930 e 1970, período considerado por essa mesma autora como o auge da exploração de balata na região.

Na década de 1970, foram introduzidos no mercado internacional materiais sintéticos, reconhecidamente mais eficazes e mais baratos, se comparados aos custos para a produção de balata na Amazônia brasileira, cuja extração exigia altos investimentos. Desde então, a balata perdeu valor comercial. Toneladas de blocos de balata apodreceram nos galpões de Belém e Manaus, de onde era exportado, e o ofício de balateiro se perdia junto.

Atualmente, o látex da balateira é extraído apenas em Monte Alegre por um pequeno grupo de balateiros com faixa etária de 40 a 60 anos de idade. Sua produção destina-se primordialmente aos artesãos de balata residentes em Monte Alegre, Santarém e Belém.

\section{Relações socioambientais pautadas no sistema de aviamento: organização do espaço e do trabalho no balatal (1930-1970)}

Entre as décadas de 1930 e 1970 na região do "baixo amazonas", oeste do Pará, milhares de homens eram arregimentados para o trabalho com a balata em seus tempos de ouro. Durante entrevista com um ex-patrão de balateiro em Alenquer, este nos conta que "teve uma época em que tinha em média dois mil homens sendo aviados" (Nelson Santiago. Entrevista cedida ao autor em Alenquer, 2013). Por ser uma profissão de muitas dificuldades e sacrifícios, o balatal ganhou características de um lugar quase que exclusivamente masculino, com raras exceções da presença feminina, como relata Nelson Santiago:

Durante a época que eu trabalhei eu soube de duas mulheres no balatal, elas foram levadas pelos maridos. Não dava bronca com elas mas as mulheres sempre perturbavam no sentido de que podiam adoecer, ficar gestante, e mulher é mais sensível pra ficar seis, sete meses no mato, por isso a gente não aceitava, mas ainda teve esses dois que levaram". (Entrevista com o Sr. Nelson Santiago em Alenquer. Cedida em julho de 2013 ao autor).

Corroborando nesse sentido, em sua dissertação intitulada "Vila de Mulher só: o trabalho invisível das mulheres em uma comunidade extrativista de balata em Monte 
Alegre" as pesquisas de Carvalho (2017), que trata da divisão sexual do trabalho indicam que "na organização do trabalho entre homens e mulheres, cabia aos homens a responsabilidade da unidade de produção e sustento da família através do balatal e, às mulheres, a casa, a roça e o cuidado e criação dos filhos" (CARVALHO, 2017. pp109).

A dinâmica de exploração e comercialização da balata, nos seus tempos áureos, foi marcada por uma forte hierarquia entre os envolvidos com o negócio, na Amazônia e no exterior, além das fronteiras nacionais. Grosso modo, pode-se dizer que na base da cadeia produtiva estavam os balateiros, os mateiros e os gateiros, na hierarquia imediatamente superior a estes, posicionavam-se sucessivamente: o chefe de turma, o encarregado, (com frequência, essas funções eram desempenhadas pelo mesmo indivíduo), o escrivão, o gerente, o patrão local, o patrão regional e, no topo, as empresas estrangeiras que financiavam toda a cadeia. Em entrevista, o senhor Nelson Santiago explica como se davam essas relações:

Eu era gerente do meu irmão. Depois da gerência eu aviei também, mas por pouco tempo. O meu pai foi seringueiro depois ele começou a cortar balata, foi um aviado, já o meu irmão foi balateiro e depois foi patrão, chamavam de aviador. Na época, todos os patrões de balateiros, tinham também seus patrões, acredito que em Monte Alegre e Almeirim também foi assim, eles não eram autônomos, sempre tinha um superior la em cima (nas capitais) que os financiava, por exemplo, em Almeirim tinha o Sr. Ofir Sadala, mas ele era financiado por outras firmas, como a Sobral Santos, os Sadala sempre trabalharam assim, eram financiados, depois eles vieram pra cá. Aqui em Alenquer era da seguinte maneira: tinha a firma IB-Sabá, era uma empresa grande que mexia com petróleo, uma firma reconhecida aqui na região, o dono era o Sr. Isaac Sabá, ele era o "gente grande" que financiava e exportava a produção de balata da região, mas tinham outros que eu não me recordo o nome. Ele financiava um cidadão de nível econômico alto daqui por nome Antônio Brito, que chamavam de Tote Brito, por que o patrão pequeno daqui não tinha condições de ir la com o senhor Isaac Sabá, que era o dono dessa grande empresa de Manaus. Os patrões daqui não tinham mérito de ir la com a empresa grande em Manaus pegar dinheiro para financiar a balata, tinha que ter um intermediário que era um homem de grandes méritos, precisava ser alguém com patrimônio grande para poder pegar um financiamento bom. Então esse Tote Brito pegava o financiamento e fazia a distribuição, ele aviava os patrões daqui que financiavam os chefes de turma aqui pela região. Eram vários patrões e chefes de turma aqui, e esse pessoal aviava os balateiros. (Entrevista com o senhor Nelson Santiago, na cidade de Alenquer. O entrevistado foi gerente e patrão de balateiro. Cedida em julho de 2013 ao autor).

O esforço de milhares de homens era orquestrado por pessoas que nunca sequer puseram os pés na região, nem mesmo sabiam das dificuldades para a extração do látex 
da balateira. O comando vinha sempre de cima para baixo, ou melhor, do importador, que encomendava toneladas de blocos de balata aos patrões regionais, sediados em Belém e Manaus. A escolha dessas capitais pelas empresas, em tese, se dava pela facilidade de acesso para fazer a intermediação entre o interior da Amazônia e o capital que animava a atividade, que por sua vez era internacional.

Os patrões regionais localizados em Belém e Manaus, direcionavam os pedidos aos patrões locais sediados nos municípios de Monte Alegre, Alenquer e Almeirim. De acordo com essas demandas, o patrão local definia o número de balateiros que seria contratado para trabalhar nos balatais numa determinada temporada e, fornecia a eles os itens necessários para a expedição e um "abono" - quantia em dinheiro cujo montante variava de acordo com a produtividade do balateiro e a confiança nele depositada pelo patrão. Então, arregimentavam os homens para o trabalho no interior da floresta.

Toda a cadeia produtiva da balata era regida pelo sistema de aviamento, que, como afirma McGrath (1999), constituiu um sistema econômico tradicional da Amazônia. Historicamente a exploração gomífera na Amazônia, seja de borracha ou de balata, foi baseada no aviamento: um sistema de adiantamento de mercadorias e dinheiro a crédito, cuja denominação teria sido cunhada na Amazônia (ARAMBURU, 1996). Praticado na região desde a época colonial, "foi no ciclo da borracha que ele se consolidou como sistema de comercialização e se constituiu em senha de identidade da sociedade amazônica" (ARAMBURU, 1996, pp91).

Aramburu (1996, p.91) descreveu essa prática como um "sistema recorrente nas formas de contrato na Amazônia brasileira" no qual o comerciante/aviador adianta bens de consumo e instrumentos de trabalho para o produtor e este paga a dívida contraída com produtos extrativos e agrícolas, caracterizando uma forma eficiente de crédito. Para o senhor Nelson Santiago:

Aviamento é aquilo que fornece! O balateiro pegava dinheiro, o abono para deixar para a família. Quando chegava na pista confusão ele tirava todo o mantimento para passar cinco, seis, sete meses no balatal e fazer a extração. Então a vida do balateiro no aviamento começava em janeiro e desciam em junho, julho, agosto, até setembro, e quando eles estavam descendo já traziam a produção (Entrevista com o senhor Nelson Antônio Santiago, na cidade de Alenquer. Cedida em julho de 2013 ao autor). 
Durante a estada do balateiro na mata, sua família também ficava autorizada a "tirar mercadorias", isto é, comprar a crédito, no comércio do patrão, que, em geral, era bem "sortido" - provido de variados gêneros de mercadorias, desde alimentos a ferramentas de trabalho e medicamentos. As famílias ficavam, de certa forma, obrigadas a comprar quase tudo nesse comércio. O patrão não negava fornecer-lhes mantimentos, pois o risco de inadimplência por parte do balateiro era muito pequeno. Além de mercadorias, algum dinheiro era fornecido às famílias.

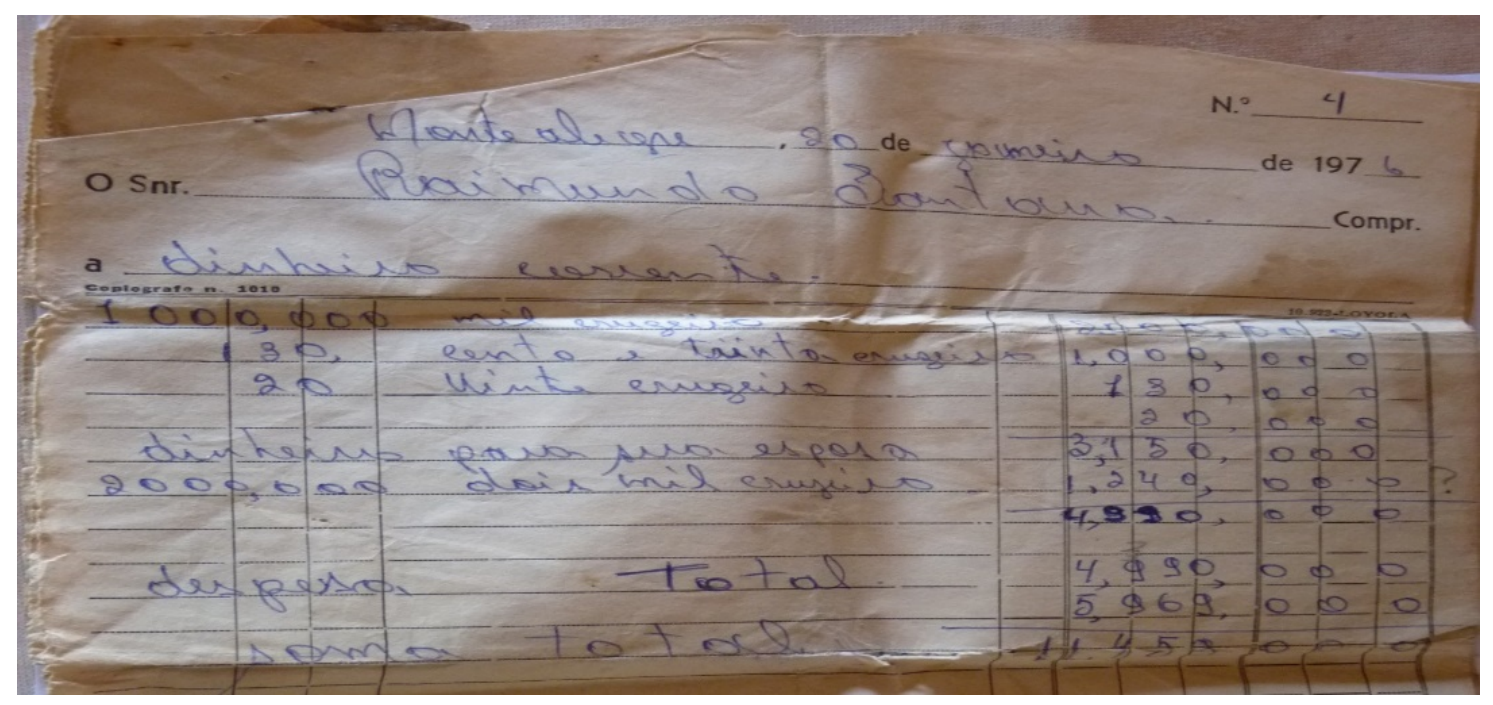

Figura 1. Prestação de contas de balateiro. Fonte: Autor. Registrado em junho de 2012 em Monte Alegre-PA.

Como pode ser observado na descrição da nota de despesas acima, alguns patrões vendiam diversos gêneros a crédito para os balateiros e pagavam uma espécie de mensalidade à família, como uma forma de adiantamento do pagamento do balateiro. Tudo isso, porém, gerava uma dívida prévia que o balateiro deveria saldar após a expedição, com a entrega do produto extraído ao patrão local.

Na prática, os materiais vendidos a crédito pelo patrão custavam aos balateiros pelo menos o dobro do preço normal (aquele cobrado regularmente a outros clientes). 0 montante devido era pago com a balata produzida, e quem lhe dava o preço era o próprio patrão. Logo, era comum que o extrativista terminasse a negociação com ganhos baixos e, às vezes, até com débitos, se não conseguisse produzir balata suficiente para cobrir as despesas assumidas.

A balata era a principal moeda de troca nas transações entre balateiros e patrões 
locais. A circulação dessa "moeda" se iniciava logo após o retorno dos extrativistas da floresta, entre os meses de junho e julho.

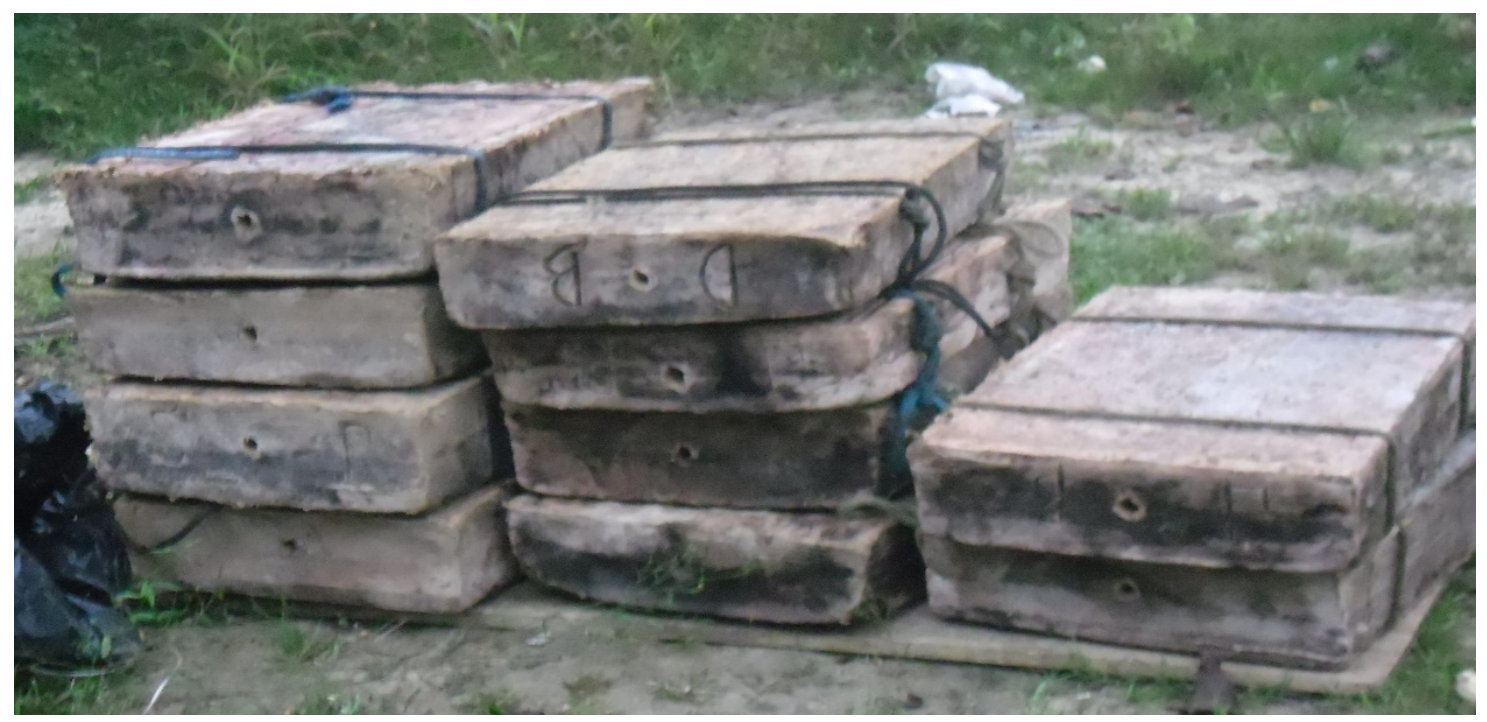

Figura 2. Foto de blocos de balata no balatal Água Azul. Fonte: o autor- registrado em Junho de 2012.

Dessa forma, cada agente da cadeia produtiva ia quitando as dívidas e renovando o crédito, alimentando um novo ciclo de endividamento e comércio. Os "processos de trabalho" (DURKHEIM, 1999) fundados no sistema de aviamento é frequentemente analisado como uma espécie de escravidão por dívida (REIS,1953; CUNHA, 1989).

O balateiro era o último elo da cadeia econômica da balata. Aparentemente era livre, mas a estrutura econômica que regia as relações de comércio local os colocava em situação semelhante à relação de servidão. Isto por que ele não tinha alternativa a não ser comprar os suprimentos necessários, a preço altíssimo, no armazém do patrão que o financiava, posto que a ele não era permitido comprar em outro armazém, senão no de propriedade de seu financiador. Deste modo, estava quase sempre em débito com o aviador, não conseguindo escapar à exploração do sistema de aviamento.

Com efeito, como sustenta Carvalho (2013, p. 385), entre patrão e balateiro estabeleciam-se relações baseadas "simultaneamente em dependência material e num senso de lealdade entre as partes". De acordo com Mauss (2003), nunca foi observado na história do direito ou da economia, trocas entre indivíduos classificados como simples, de bens ou produtos. Primeiro porque não podem ser chamados de "indivíduos' e sim de "coletividades que se obrigam mutuamente, trocam e contratam'. 
Sendo assim, existem relações que não estão apenas no viés "compra e venda', mas sim, se classificam a partir de valores sentimentais que se interligam com costumes que em determinadas épocas do ano afloram. E situações como "ficar em dívida" corresponde ao sentimento de que é preciso pagar o que se deve, é preciso aceitar o que é oferecido, o não aceite pode ser considerado uma ofensa, é preciso retribuir o que recebeu (MAUSS, 2003).

Dessa forma, quando se parte da análise do aspecto material das realidades sociais, e das forças produtivas de que um grupo societário dispões para agir sobre a natureza que o cerca, é possível verificar a existência de dois componentes intimamente ligados: uma parte material, representado pelos utensílios, força de trabalho, etc. e uma parte ideal reconhecida como as representações da natureza, lealdade, regras de conduta, uso responsável dos utensílios, etc. Essas representações se constituem num norte orientador que mobiliza a ação material que se efetua através de conjuntos de ações ordenadas que compõem os chamados "processos de trabalho" (GODELIER, 1981).

\section{Trabalho e conhecimentos tradicionais para a extração de balata}

A vida no balatal, como contado por dezenas de balateiros entrevistados, nunca foi fácil. Apesar de se identificarem como homens fortes e corajosos, eles próprios assumem o quão difícil e arriscado é o seu ofício:

Quando a gente subia, ia todo tempo de canoa, colocava toda a mercadoria dentro [da canoa], tudo enlatado e subia. Numa turma eram quatro balateiros e o chefe de turma, era no máximo cinco em cada turma, por que era o que cabia na canoa. Subia sempre de vara e remo, a carga era o tempo todo nas costas. Eram três meses de subida, três de baixada e três no trabalho. Nove meses de trabalho, isso logo que começou o negócio da balata e começaram a subir aqui de Alenquer. Depois já subia mais rápido, quando o pessoal começou a aprender melhor as manhas das cachoeiras, ai ficou mais rápido. Eu não cheguei a ir no tempo dos aviões, só fui quando só subia de canoa. A gente sofria durante esses nove meses com carga nas costas o tempo todo, quando estávamos subindo, la no alto carregando os blocos e pra descer tinha que segurar os blocos para não se perderem nas cachoeiras. Só tinha sossego no barraco, quando a gente ia caçar ou quando ia cozinhar leite (látex da manilkara bidentata). No trabalho com a balata a gente se aparelha (se equipa com as ferramentas para subir e sangrar a árvore) para subir na balateira e vai cortando, o embutidor fica embaixo e o leite vai descendo. As vezes se cortava três, quatro balateiras, era o máximo que se conseguia cortar num dia. No fim do dia era recolhido o leite do embutidor, 
colocava no carregador, colocava ele num paneiro, joga nas costas e leva para o barraco. No barraco tinha um tanque feito para colocar esse leite, uma bacia que é igual um forno, era só botar fogo embaixo e fiar mexendo, quando começava a endurecer era só colocar um pouco de água e continuar mexendo. Depois tinha que puxar o leite. Tinha um giral pra fazer isso, nas laterais do giral tinha dois pedaços de madeira com forquilha que eram afincados no chão, na forquilha tinha uma travessa que ficava por cima do giral. É só tirar o leite do forno, joga no giral e fica puxando na travessa que fica por cima. Nesse momento a prensa já deve estar pronta. Passa várias horas puxando o leite quente, essa puxação é para tirar todas as folhas, pedaço de pau, pedra, todas as impurezas, para depois jogar na prensa, a prensa já é feita com o nome do dono gravado nela, para o bloco já sair com o nome do dono. Eu tive essa lida por dez anos. (Entrevista com o senhor Bernaldino Elias, na cidade de Alenquer. O entrevistado foi balateiro. Cedida em julho de 2013 ao autor).

A execução dessa parte do processo, de longe aparenta ser a tarefa mais perigosa, balateiros relatam algumas experiências decorrentes da extração do látex da manilkara bidentata:

\begin{abstract}
Tinham muitas histórias sobre essa época da balata. Sei que morrer na balateira, morreu. A chaveta sacou do arame, o arame abriu e o caboco caiu de muito alto, ele estava longe dos outros parceiros, quando foram achar, bicho já tinha comido tudo ele, só tina os ossos debaixo da balateira. Outro caso foi de dois irmãos que moravam perto de nós. Um deles saiu pra cortar balateira e não sei o que ele fez que o arame abriu e ele despencou la de cima. Esperamos a tarde toda e quando deu seis horas da tarde fomos atrás dele junto com seu irmão, por que lá era perigoso. Entramos na picada que ele tinha entrado, de longe eu vi ele pendurado, chegando embaixo da balateira estava cheio de sangue, ele morreu pendurado de cabeça pra baixo. $O$ arame abriu e ele não tinha como se apoiar em nada, ficou pendurado de cabeça pra baixo e todo o sangue dele começou a escorrer pelo nariz, ouvido (Entrevista com o senhor Bernaldino Elias, na cidade de Alenquer. $O$ entrevistado foi balateiro. Cedida em julho de 2013 ao autor).
\end{abstract}

Compreende-se que a atividade de extração de balata requer determinadas habilidades físicas e cognitivas, exige verdadeiras cadeias de esquemas práticos e de percepção que trabalham como um organismo vivo de construção da realidade e divisão social do trabalho. Para Durkheim (1999), a base dos processos de trabalho está nas ordens morais e sociais, as quais interligam indivíduos para além dos momentos que passam juntos executando uma tarefa. São solidários uns com os outros, em uma solidariedade que os faz se desenvolverem juntos em profundas relações.

Os saberes técnico-culturais que constituem o saber-fazer da exploração de balata são repassados de geração a geração nas comunidades tradicionais do interior da 
Amazônia, compondo um vasto campo de "etnoconhecimento" (SILVA, 2014), apreendido com a vivência cotidiana e interação direta com o meio que os cerca, a observação de fenômenos naturais e as experiências trocadas com populações que já viviam a muito tempo antes na região, como o contato com os índios apalay que viveram por muito tempo na cabeceira do rio Maicuru.

O tipo de reprodução de saberes tradicionais realizado por balateiros envolve "representações simbólicas, conhecimentos intergeracionais, adaptações às mudanças impostas pelo meio, adquiridos num processo social de aprendizagem" (SILVA NETO, 2014, p. 87).

Verifica-se em Godelier (1981), que um processo de trabalho comporta muitas vezes atos simbólicos pelos quais se age não sobre a natureza visível, como o uso de utensílios e ferramentas, mas sobre forças invisíveis que controlam a natureza e são reconhecidos e respeitados como podendo conceder ou negar ao homem o que ele busca da natureza: uma boa safra, boa caçada, etc. Essa parte mítica do processo de trabalho constitui uma realidade social tão real como as ações materiais sobre a natureza. Os modos ideais de interpretar o mundo, nas cosmologias das populações tradicionais, estão quase sempre tão ligados aos processos de trabalho quanto o meio prático-material, mas só possuem significado para o grupo que assim idealiza e, quando situados em seu espaço de trabalho.

\section{Ressurgimento do ofício a partir do surgimento do artesanato comercial de miniaturas em balata}

No período correspondente ao processo de decadência do comércio da balata, 1950-1970, surgiu em Monte Alegre-PA, através de dois balateiros a ideia de fazer artesanato de balata para vender nos navios que ancoravam no porto da cidade. Os produtos desse trabalho eram miniaturas de animais nativos que representavam o cotidiano na floresta. De um lado tinham intenção de "aproveitar" a balata que apodrecia nos galpões da cidade, de um outro, era uma forma de ganhar algum dinheiro e contribuir no sustento da família.

O uso de balata para a produção de artesanato, a partir de meados dos anos 1960, foi adquirindo importância comercial (CARVALHO, 2011). Em algumas famílias de 
Monte Alegre, sob a influência daqueles dois balateiros, foi se constituindo uma geração de artesãos especializados que consolidaram e difundiram na região a tradição de "fazer bichinhos de balata", estimulando também a continuidade do ofício de balateiro (SILVA, 2016).

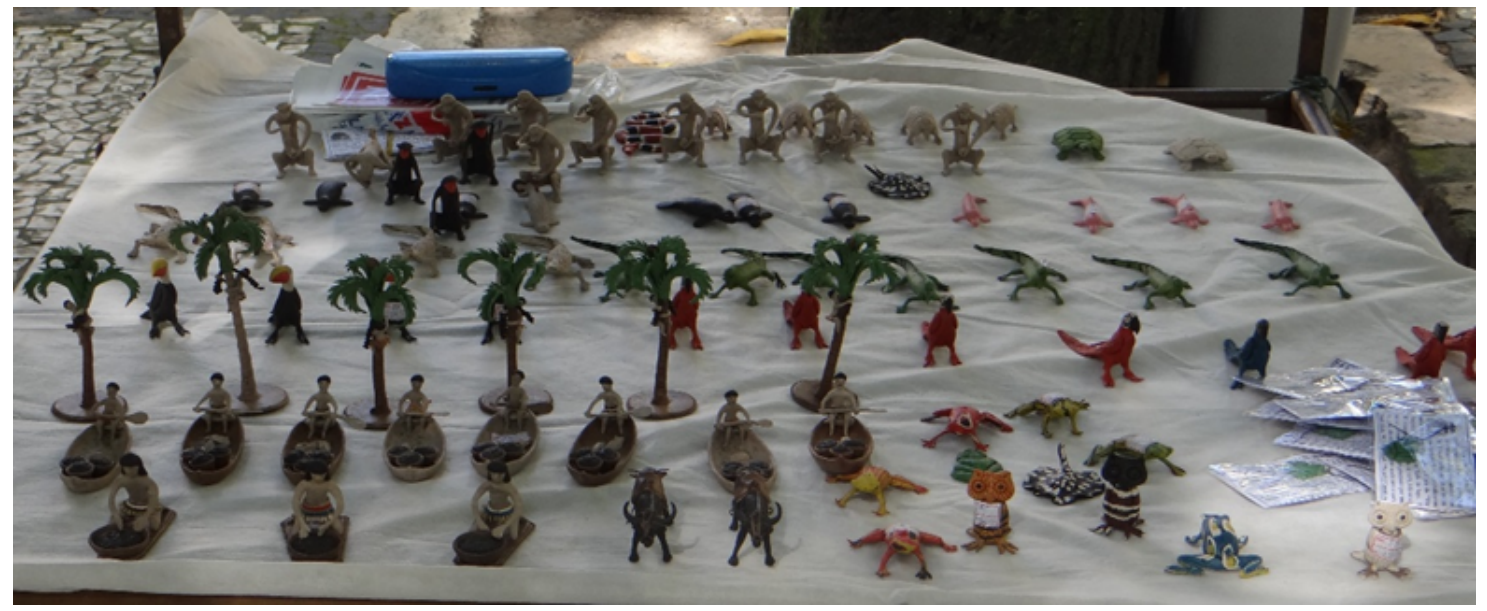

Figura 3. Fotos de artesanato em balata na Praça da República-Belém/PA. Fonte: Autor abril de 2015.

A confecção dos "bichinhos de balata", como é popularmente conhecido o artesanato em balata na cidade de Monte Alegre, já era conhecido pelos balateiros que relatam ter tomado conhecimento dessa prática a partir do contato com os índios Apalay que habitavam a região dos balatais do Rio Maicuru.

Os balateiros passaram a incorporar essa prática e confeccionar utensílios como bolsas e chinelos do látex, para usarem no balatal. No entanto, a atividade não assumia caráter econômico. Por longo tempo, essa produção foi o jeito encontrado pelos balateiros, em presentear os parentes e amigos, e mostrar o seu ponto de vista do espaço de trabalho.

A confecção de objetos a partir de látex é conhecida desde 1743 quando segundo Bueno (2012), o naturalista francês Charles Marie de La Condamine em sua expedição pelo rio Amazonas observou que esse líquido, após coagulado, se transformava numa substância maleável, de elasticidade e impermeabilidade nunca visto, a qual os índios moldavam na forma de seringas, botas, garrafas e brinquedos. Reiterando a antiguidade dessa atividade, Simonian (2006), afirma que cabia aos indígenas o domínio e a confecção de produtos com látex vegetal desde muito antes do seu conhecimento e 
exploração no mercado internacional. Para essa autora, foram os Omáguas que descobriram o modo de utilização da seiva das sapotáceas para uso no preparo e fabricação de sandálias, braceletes e afins.

Como resultado da atitude empreendedora dos dois balateiros o ofício de balata ressurgiu em Monte Alegre, desta vez, sem pretensão de se tornar um novo ciclo comercial, mas apenas para a manutenção e reprodução do artesanato, do modo cultural de fazer "bichinhos de balata".

Em Belém e Santarém, especialmente, o comércio das miniaturas é intenso, e elas são vendidas até mesmo para clientes no exterior. Como consequência, a demanda de balata tem experimentado algum crescimento nos últimos anos, e os balateiros também têm obtido reconhecimentos por seu trabalho. Segundo Silva (2016), esse grupo de homens é a única turma de que se tem conhecimento na região que ainda realiza a exploração da balata, porém não todos os anos, como ocorria no passado.

\section{Considerações Finais}

Diversos autores têm apontado a importância da presença de povos tradicionais na floresta amazônica como atores de diversificação e preservação da natureza ao mesmo tempo em que apontam a necessidade de preservação de seus saberes tradicionais como garantia de sua reprodução sociocultural (DIEGUES, 2001; BALÉE, 2008, 2014; LITTLE, 2002). Pode-se afirmar que os balateiros desempenham um papel importante no processo de conhecimento sobre a floresta amazônica e seus recursos. A importância da preservação dos conhecimentos desse grupo se reconhece em um saber-fazer transmitido ao longo de gerações por meio da oralidade.

O contato desses homens com a natureza desde os 8, 10 anos de idade, se deu por quase toda uma vida, desde muito novos já eram enviados ao trabalho no balatal, essas experiências de muitos anos formaram um conhecimento prático fundamental para a sobrevivência na floresta. É deste contato íntimo com a natureza da Amazônia que se cunhou a identidade social dos balateiros, resultando numa representatividade tamanha que passou a fazer parte do contexto social e histórico das cidades envolvidas no negócio. 
Observa-se que o impacto ambiental da exploração da balata é mínimo, ao mesmo tempo em que desempenha um importante papel na captação de recursos financeiros para a reprodução social do grupo de extrativistas e das famílias que produzem artesanato de balata.

Apesar das décadas de exploração da balata, os espaços de floresta ocupados como ambiente de trabalho e morada, encontram-se até hoje preservados. A exploração sustentável dos balatais foi possível graças ao "etnomanejo" - nos moldes usados por Silva Neto $(2014, \mathrm{p} 8)$, aprendido e reproduzido pelos balateiros por gerações.

Os conhecimentos tradicionais sustentáveis e as técnicas de manejo utilizadas por balateiros, se fundam no contato direto com a natureza e as experiências vividas desde muito novos. As inter-relações que envolvem balateiros, artesãos e floresta, constituem um modelo de sustentabilidade pautado em conhecimentos locais sobre as dinâmicas da floresta e as transformações naturais que ocorrem com a sazonalidade amazônica. Dessas relações constrói-se um modelo de sustentabilidade que é tecido a partir de complexas relações entre o meio cultural e o natural. Todas as inter-relações que envolvem, balateiros, artesãos e a floresta, faz surgir um emaranhado de tecido que culturaliza a natureza e cria uma sociobiodiversidade (SANTILLI, 2005), classificatória e domesticadora dos bens naturais disponíveis.

É importante ressaltar a importância da presença dos artesãos de balata, sem os quais a extração de balata já teria desaparecido a anos. A demanda efetiva por balata vem do grupo de artesãos, especialmente os residentes em Belém, que sobrevivem exclusivamente da produção do artesanato de balata para a venda em várias cidades do Pará, alguns estados brasileiros e no exterior.

O domínio de todos os saberes sobre a realidade local da floresta amazônica em que trabalham e vivem, constituem um importante acervo cultura dos balateiros, tendo nos artesãos de balata a protagonização da arte de confeccionar produtos artesanais de grande valor cultural para a região do baixo Amazonas.

As relações estabelecidas com a floresta são de respeito e pertencimento ao lugar, permeadas por um conjunto de valores éticos e morais que orienta todo o processo de exploração e vivência na mata. Esses valores só fazem sentido para o próprio grupo, 
posto que são orientadores das ações dos extrativistas, especialmente no processo de "sangrar" a árvore.

O cuidado e respeito com a natureza ficam explícitos no discurso dos balateiros, isso se observa claramente quando falam sobre seu trabalho: "o terçado de sangrar tem que ser bem amolado (afiado), pra que a balateira não sinta o corte. Se for cego (desamolado) a balateira sente, ai ela fica vermelha e não solta leite" (Entrevista com o balateiro Bojó - Monte Alegre, cedida em Abril de 2012 ao autor). Esses ideais que compõem a mentalidade social do grupo exercem papel ordenador das relações de trabalho, efetuando a divisão de tarefas e as regras internas que emergem das relações estabelecidas.

As populações tradicionais que mantém uma estreita relação com o espaço natural, relacionam-se com este último de forma a ultrapassar sua dimensão prática e material, resultando numa forma de conhecimento que reúne as esferas do material e do imaterial, onde juntos compõem a realidade social vivida (GODELIER, 1981).

Os saberes de balateiros, assim como os de toda comunidade tradicional, conforme visto anteriormente, constituem fenômenos complexos construídos socialmente a partir de práticas e experiências culturais, relacionadas ao espaço social, aos usos, costumes e tradições. Por ser coletivamente construído, possuem características marcantes de relações compartilhadas, de intercâmbio e de solidariedade.

\section{Referências}

ARAMBURU, Mikel Otazu. Aviamento, modernidade e pós-modernidade no interior amazônico. Revista Lusotopie. 1996, p.189-206.

BALÉE, William, Sobre a Indigeneidade das Paisagens. Artigo apresentado no VI Congresso Mundial de Arqueologia, no Simpósio de Arqueologia e Ecologia Humana no século XXI, organizado por H. Barton e M. Davies, em Dublin, Irlanda, em 03/07/2008.

William; et al. Florestas antrópicas no Acre: inventário florestal no geoglifo Três Vertentes, Acrelândia - Amazônia., Rev. Antropol. (Online) 6 (1): 140 - 169, 2014. BRASIL, Ministério da Ciência e da Tecnologia. Desenvolvimento Científico e Tecnológico. Museu Paraense Emílio Goeldi. A CIÊNCIA dos mêbêngôkre: Alternativas contra a destruição. Exposições Científicas. Museus Científicos. Belém, 1987. p. 69.

Ministério do Meio Ambiente (MMA). Unidades de Conservação. Floresta Estadual do Paru. Disponível em <http://sistemas.mma.gov.br/cnuc/index.php?ido= 
relatorioparametrizado.exibeRelatorio\&relatorioPadrao $=$ true\&idUc $=1038>$ S.D. Acesso em 06.01.2018.

BUENO, Ricardo. Borracha na Amazônia: as cicatrizes de um ciclo fugaz e o inícioda industrialização. 1ª . ed. Quattro Projetos. Porto Alegre, 2012.

CARVALHO, Amasa Ferreira. "Vila de mulher só": o trabalho invisível das mulheres em uma comunidade extrativista de balata em Monte Alegre/Pará, Santarém, 2017.

CARVALHO, Luciana G. de. Balata: Amazônia em miniatura. Rio de Janeiro: IPHAN, CNFCP, 2006.

Luciana G. Memórias de trabalho: balateiros de Monte Alegre. Rio de Janeiro: IPHAN, 2011.

Luciana G. Relações de trabalho nos balatais do Pará. Horizontes Antropológicos, Porto Alegre, ano 19, n. 39, p. 373-400, jan./jun. 2013.

CUNHA, Euclides. da. A Margem da História. São Paulo: Martins Fontes. In: DEAN, Warren. A Luta pela Borracha no Brasil: um estudo de história ecológica. Nobel: São Paulo, 1989.

DANTAS, Fernando Antonio de Carvalho. Base jurídica para a proteção dos conhecimentos tradicionais. Revista CPC, São Paulo, v.1, n.2, p.80-95, maio/out. 2006.

DIEGUES, Antonio Carlos Santana. O mito moderno da natureza intocada. $3^{\mathrm{a}}$ ed., Ed. Hucitec - Núcleo de apoio à pesquisa sobre populações humanas e áreas úmidas brasileiras/USP, São Paulo, 2001.

DURKHEIM, Émile. Da divisão do trabalho social. Tradução de Eduardo Brandão. São Paulo: $2^{\mathrm{a}}$ ed. Martins Fontes, 1999.

GODELIER, M. Antropologia. Edgard de Assis Carvalho (Org.). Tradução de Evaldo Sintoni et al. São Paulo: Ática, 1981.

M. Modos de Produção, Relações de Parentesco e Estruturas Democráticas. In: CARVALHO, Edgard de A. (org.). Godelier. São Paulo: Ática, 1981.

LITTLE, Paul E. Territórios Sociais e Povos Tradicionais no Brasil: Por uma antropologia da territorialidade. Série Antropologia. Universidade de Brasília. Brasília, 2002.

MAUSS, Marcel. Sociologia e Antropologia. 10ª ed. São Paulo: Cosac Naify, 2003.

MCGRATH, David. Parceiros no Crime: o regatão e a resistência cabocla na Amazônia tradicional. Novos Cadernos NAEA vol. 2, n 2 - dezembro, 1999.

MEIRA, Silvio. Os balateiros do Maicuru. Rio de Janeiro. ed. Francisco Alves/Prómemória. 1984.

MOORE, JR, Barrington. Injustiça: as bases sociais da obediência e da revolta. Brasilienses: São Paulo, 1987.

OLIVEIRA, Roberto Cardoso de. O trabalho do antropólogo, 2 ed. São Paulo, Ed. UNESP, 2000.

PARÁ, Instituto do Homem e Meio Ambiente da Amazônia. Planos de Manejo. Resumo executivo. Disponível em 
$<$ http://imazon.org.br/PDFimazon/Portugues/calha_norte/planos_de_manejo /ResumoEXC_PM_PARU_WEB.pdf> S.D. Acesso em 06.01.2018.

Secretaria Estadual de Meio Ambiente: Florestas Estaduais da Calha Norte. Disponível em: <https://www.semas.pa.gov.br/diretorias/areas-protegidas/florestasestaduais-da-calha-norte-faro-paru-e-trombetas/floresta-estadual-de-paru/> S.D. Acesso em 06.01.2018.

POLLAK, Michael. Memória e identidade social. Estudos históricos, Rio de Janeiro, vol. 5. $\mathrm{n}^{\circ} 10,1992$.

REIS, Arthur Cezar Ferreira. O seringal e o seringueiro. Rio de Janeiro: Serviço de Informação Agrícola, 1953.

SANTILLI, Juliana. Socioambientalismo e novos direitos. São Paulo: Petrópolis. 2005.

SILVA NETO, Nirson Medeiros da. Quebradeiras e carvoeiros: a transformação do extrativismo de coco babaçu nas terras do Araguaia-Tocantis. Saarbrüken. Novas Edições Acadêmicas, 2014.

SILVA, Marcelo Araújo da. Condições de efetivação dos Direitos Ambientais de um grupo de balateiros diante das Concessões Florestais na Floresta Estadual do Paru. Trabalho de Conclusão de Curso (Graduação em Direito). Universidade Federal do Oste do ParáUfopa. 2016, 99 p.

SILVA, Rubens Elias da. Coletoras de sementes do Tapajós: mulheres, saberes práticos, relações de gênero e a floresta. Vivência. Revista de Antropologia, $n^{\circ} 43$. p. 85-95, 2014.

SIMONIAN, Ligia T. L. Relações de Trabalho e de Gênero nos Balatais da Amazônia Brasileira. In: SCHERER, Elenise OLIVEIRA, José Ademir de (Orgs.). Amazônia: Políticas públicas e Diversidade cultural. Rio de Janeiro: Garamond, 2006.

Weinstein, Bárbara. A borracha na Amazônia: expansão e decadência (1850- 1920). São Paulo: HUCITEC : Editora da Universidade de São Paulo,1993.

WITKOSKI, Antônio Carlos. Terra, floresta e água: os camponeses amazônicos e as formas de uso de seus recursos naturais. $1^{\text {a }}$ ed. EDUA: Manaus, 2006. 